\title{
PENERAPAN PIDANA DENDA DALAM TINDAK PIDANA KEIMIGRASIAN \\ PASAL 71 JO. PASAL 116 UNDANG-UNDANG NO. 6 TAHUN 2011 TENTANG KEIMIGRASIAN (PUTUSAN NO.11/Pid.C/2016/PN.JKT.BRT)
}

\author{
Ali Imron, Elis Novitasari \\ Fakultas Hukum Universitas Pamulang \\ aliimron@gmail.com
}

\begin{abstract}
Immigration is a crime that violates the law and is protected by the law with immigration activities. The application of criminal fines for immigration offenses by not carrying out their obligations as foreigners residing in the Territory of the Republic of Indonesia, as requested by Article 71 of Law No. 6 of 2011 concerning Immigration, which reads "Every Foreigner residing in Indonesian territory is obliged to Invite travel documents or residence permits that are requested for refunds by an Immigration Officer approved for Immigration supervision". Regarding immigration actions which emphasize the sanctions of his government, so considering the consideration of the formulation of court sentences will result in ineffectiveness of immigration laws that are less effective because foreigners (convicts) can choose the appropriate protection with legal entities.
\end{abstract}

\section{Keywords: Criminal Fines, Immigration}

\begin{abstract}
ABSTRAK
Tindak pidana keimigrasian adalah tindak pidana serangkaian perbuatan terlarang oleh Undang-Undang dan tercela dalam kaitannya dengan kegiatan keimigrasian. Penerapan pidana denda terhadap tindak pidana keimigrasian dengan tidak melakukan kewajibannya sebagai orang asing yang berada di Wilayah Negara Republik Indonesia, sebagaimana yang dimaksud Pasal 71 Undang-Undang No. 6 Tahun 2011 tentang Keimigrasian, yang berbunyi "Setiap Orang Asing yang berada di wilayah Indonesia wajib memperlihatkan dan menyerahkan dokumen perjalanan atau izin tinggal yang dimilikinya apabila diminta oleh Pejabat Imigrasi yang bertugas dalam rangka pengawasan Keimigrasian”. mengenai tindakan keimigrasian yang lebih menekankan sanksi administratifnya, sehingga menimbulkan asumsi bahwa rumusan sanksi pidana ini dipandang akan menyebabkan daya pencegahan didalam undang-undang keimigrasian kurang efektif karena orang asing (terpidana) dapat memilih sanksi pidana denda daripada pidana badan.
\end{abstract}

\section{Kata Kunci : Pidana Denda, Imigrasi}




\section{PENDAHULUAN}

Kemajuan dan perkembangan di segala bidang mulai dari teknologi, informasi dan ekonomi menyebabkan batas-batas negara semakin hilang dengan banyaknya lalulintas orang yang masuk dan keluar wilayah Indonesia dan hal ini sangat sulit untuk dicegah. Hukum Keimigrasian merupakan bagian dari sistem hukum yang berlaku di Indonesia, bahkan merupakan subsistem dari Hukum Administrasi Negara (Santoso, 2004 : 1). Keimigrasian sebagai penyelenggaran administrasi Negara yang mengatur dan mengawasi lalulintas orang yang masuk dan keluar wilayah Negara Republik Indonesia untuk menjaga stabilitas negara dan ketahanan nasional, keimigrasian memiliki peran yang sangat penting sebagai penyelanggaraan administrasi negara yang menjaga tegaknya kedaulatan negara.

Keimigrasian merupakan gerbang suatu negara dalam menjaga kedaulatnnya serta menjaga stabilitas negaranya untuk tetap terjaga keamanan dan keteraturan dalam hal lalulintas keluar masuknya orang masuk kedalam suatu negara tersebut. Fungsi keimigrasian merupakan fungsi penyelenggaraan administrasi negara atau penyelenggaraan administrasi pemerintahan, oleh karena itu sebagai bagian dari penyelenggaraan kekuasaan eksekutif, yaitu fungsi administrasi negara dan pemerintahan, maka hukum keimigrasian dapat dikatakan bagian dari bidang hukum administrasi Negara (Manan, 2000).

Ketika orang asing yang bukan Warga Negara Indonesia masuk ke wilayah Negara Republik Indonesia harus memiliki dokumen perjalanan.

Dokumen Perjalanan adalah dokumen resmi yang dikeluarkan oleh pejabat yang berwenang dari suatu negara, Perserikatan Bangsa-Bangsa, atau organisasi internasional lainnya untuk melakukan perjalanan antarnegara yang memuat identitas pemegangnya.

Dokumen perjalanan yang
dimaksud adalah dikeluarkan oleh masing-masing negara. Orang asing masuk ke wilayah Indonesia memiliki beberapa kepentingan dan tujuan yang berbeda-beda yang dapat dilihat dari jenis visa yang diberikan oleh pihak keimigrasian dan Kantor Kedutaan Republik Indonesia yang berada di Negara-Negara lain.

Dengan adanya ketentuan hukum mengenai keimigrasian dalam hal ini Tindak pidana keimigrasian yang dilakukan oleh warga negara asing perlu mendapat perhatian dan pengawasan yang intensif agar tidak adanya penyalahgunaan ijin yang diberikan dalam memasuki wilayah Indonesia, karena akan berdampak terhadap kekokohan dari kedaulatan negara.

\section{METODE PENELITIAN}

Jenis penelitian ini merupakan penelitian hukum normatif (normative legal research), untuk mengidentifikasi dan menganalisis faktor hukum yang menjadi kendala pada tindakan-tindakan hukum dari suatu hukum administrasi, serta mengkaji ulang konsep yang menjadi penyebabnya.

Dalam penelitian ini pendekatan yang digunakan adalah pendekatan perundang-undangan dan pendekatan kasus. Kedua pendekatan ini digunakan untuk mengetahui kesesuaian antara aturan-aturan dan kenyataan-kenyataan yang terjadi.

\section{PERMASALAHAN}

Untuk memberi arahan pada penulisan ini maka bagaimanakah dasar pertimbangan hakim dalam pemberian sanksi pidana denda terhadap pelaku tindak pidana keimigrasian berdasarkan keputusan

Nomor. 11/Pid.C/2016/PN.JKT.BRT dan bagaimanakah penerapan pidana denda berdasarkan keputusan Nomor. 11/Pid.C/2016/PN.JKT.BRT tidak bertentangan dengan KUHP?

\section{PEMBAHASAN \\ Dasar pertimbangan hakim dalam pemberian sanksi pidana denda terhadap pelaku tindak pidana keimigrasian berdasarkan keputusan Nomor. 11/Pid.C/2016/PN.JKT.BRT}

Dalam teks Bahasa Belanda dari KUHP dapat ditemukan istilah starbaarfeit. Tim Penerjemah Badan 
Pembinaan Hukum Nasional dalam menerjemahkan KUHP dari Bahasa Belanda ke Bahasa Indonesia, menerjemahkan istilah starbaarfeit sebagai tindak pidana dan di KUHP sendiri tidak diberikan definisi terhadap istilah tindak pidana atau starbaarfeit. Karenanya, para penulis hukumm pidana telah memberikan pendapat mereka masing-masing untuk menjelaskan tentang arti dari istilah tersebut.

Dalam unsur-unsur tindak pidana, umumnya dikemukakan terlebih dahulu pembedaan dasar antara unsur (bagian) perbuatan dan unsur (bagian) kesalahan (pertanggungjawaban pidana). Unsur (bagian) perbuatan ini sering juga disebut unsur (bagian) objektif sedangkan unsur (bagian) kesalahan sering juga disebut unsur (bagian) subjektif.

Adapun yang termasuk kedalam Unsur subjektif dari sesuatu tindak pidana itu adalah antara lain: (Lamintang, 1996 : 184.)

1. Kesengajaan atau ketidaksengajaan (dolus/culpa)

2. Maksud atau voornemen pada suatu percobaan atau poging seperti yang dimaksud dalam Pasal 53 (1) KUHP

3. Macam - macam maksud (oogmerk) seperti yang terdapat misalnya di dalam kejahatan pencurian, penipuan, pemerasan, pemalsuan

4. Merencanakan terlebih dulu (voorbedachte raad) seperti yang misalnya terdapat di dalam kejahatan pembunuhan menurut Pasal 340 KUHP

5. Perasaan takut (vrees) seperti antara lain terdapat di dalam rumusan tindak pidana berdasarkan Pasal 308 Kitab Undang - Undang Hukum Pidana (KUHP).

Sedangkan yang termasuk kedalam unsur objektif dari sesuatu tindak pidana itu adalah antara lain:

1. Sifat melanggar hukum

2. kualitas dari si pelaku

3. kausalitas, yakni hubungan antara sesuatu tindakan sebagai penyebab dengan sesuatu kenyataan sebagai akibat.
Pengadilan Negeri Jakarta Barat yang memeriksa dan mengadili perkara pidana dalam tingkat pertama dengan acara pemeriksaan khusus telah menjatuhkan putusan sebagai berikut dalam perkara terdakwa : Nama : YAYA ABRAHAM NYANG. Untuk tersangka tidak dilakukan penahanan tetapi terhadap tersangka dilakukan Tindakan Pendetensian. Tindakan Pendetensian adalah Tindakan Administratif Keimigrasian yang dilakukan untuk kepentingan penyelidikan tindak pidana keimigrasian.

Tersangka ditempatkan di dalam Ruang Detensi di Kantor Imigrasi Kelas I Khusus Jakarta Barat. Berdasarkan Pasal 1 Angka 33 Undang-Undang Nomor. 6 Tahun 2011 Tentang Keimigrasian Rumah Detensi Imigrasi adalah "Unit pelaksana teknis yang menjalankan Fungsi Keimigrasian sebagai tempat penampungan sementara bagi Orang Asing yang dikenai Tindakan Administratif Keimigrasian”. Sedangkan menurut Pasal 1 Angka 34 UndangUndang Nomor. 6 tahun 2011 Tentang Keimigrasian Ruang Detensi Imigrasi adalah "Tempat penampungan sementara bagi Orang Asing yang dikenai Tindakan Administratif Keimigrasian yang berada di Direktorat Jenderal Imigrasi dan Kantor Imigrasi”.

Dalam Tindakan Pidana Keimigrasian dengan tersangka Yaya Braham Nyang Tindakan Pendentesian dilakukan Ruang Ditens di Kantor Imigrasi Kelas I Khusus Jakarta Barat sejak tanggal o2 Juni 2016 sampai dengan selesai, setelahnya dibuatkan Berita Acara Pendetensian tertanggal o2 Juni 2016 dan Surat Perintah Pendetensian Nomor: W10.IMI.IMI.2GR.02.03-2265A, tanggal o3 Juni 2016.

Tersangka tidak didampingi Penasehat Hukum sesuai dengan Surat Berita Acara Penolakan Untuk Didampingi Penasehat Hukum tertanggal 17 Juni 2016 melalui pernyataan tersangka di atas materai Rp. 6.000,-. Bahwa untuk sementara menolak didampingi penasehat hukum dan akan dihadapi sendiri dengan disaksikan oleh pejabat yang berwenang.

Pada hari Selasa, 31 Mei 2016 sekitar pukul $\mathbf{1 8 . 0 0}$ berdasarkan surat 
perintah

W10.IMI.IMI.2.GR.03.02-2176 Tanggal $30 \quad$ Mei 2016 dan

W10.IMI.IMI.2.GR.03.02-2200 Tanggal 31 Mei 2016 melakukan pengawasan dan pemeriksaan keimigrasian terhadap WNA di pemukiman Grogol Petamburan Jakarta Barat. Petugas Keimigrasian Kelas I Khusus Jakarta Barat menemukan seseorang yang diduga berasal dari Benua Afrika, pada saat itu Petugas meminta orang asing tersebut untuk menunjukkan Dokumen Perjalanan (Paspor) dan Kartu Izin Tinggal (KITAS) yang dimilikinya, yang bersangkutan tidak dapat menunjukkannya dan memperlihatkan.

Orang asing tersebut bernama Yaya Abraham Nyang, berusia 28 tahun lahir di Banjul, Gambia pada tanggal 12 Januari 1988, pekerjaan sebagai mekanik, Agama Islam. Masuk wilayah Negara Republik Indonesia sekitar bulan Desember 2015 melalui Bandara Soekarno-Hatta Jakarta, menggunakan pesawat Qatar dan tiba di Jakarta pada malam hari. Masuk wilayah Indonesia menggunakan Visa Kunjungan. Menurut keterangan Orang asing tersebut bahwa yang bersangkutan tidak dapat menunjukkan Dokumen Perjalanannya (Paspor) dikarenakan sedang dititipkan dan dibawa oleh temannya untuk membeli tiket pesawat pulang ke Gambia. Yang bersangkutan tidak pernah keluar dari wilayah Negara Republik Indonesia sejak terakhir masuk wilayah Indonesia pada Desember 2015. Karena Orang asing tersebut tidak dapat menunjukkan Dokumen Perjalanannya (Paspor), kemudian terhadap orang asing tersebut dibawa ke Kantor Imigrasi Kelas I Khusus Jakarta Barat guna pemeriksaan lebih lanjut. Untuk tersangka tidak dilakukan penahanan tetapi terhadap tersangka dilakukan Tindakan Pendetensian. Tindakan Pendetensian adalah Tindakan Administratif Keimigrasian yang dilakukan untuk kepentingan penyelidikan tindak pidana keimigrasian. Tersangka ditempatkan di dalam Ruang Detensi di Kantor Imigrasi Kelas I Khusus Jakarta Barat. Dalam Tindakan Pidana Keimigrasian dengan tersangka Yaya Braham Nyang Tindakan Pendentesian dilakukan Ruang Ditens di Kantor
Imigrasi Kelas I Khusus Jakarta Barat sejak tanggal o2 Juni 2016 sampai dengan selesai, setelahnya dibuatkan Berita Acara Pendetensian tertanggal o2 Juni 2016 dan Surat Perintah Pendetensian Nomor: W10.IMI.IMI.2GR.02.03-2265A, tanggal o3 Juni 2016. Berdasarkan Surat Perintah Penyidikan Nomor. Sprindik14/VI/2016/DIKKIM/JAKBAR, Tanggal 14 Juni 2016, melakukan penyidikan atas Tindak Pidana Keimigrasian dengan perkara dugaan orang asing yang diduga tidak dapat memperlihatkan dan menyerahkan dokumen perjalanan dan ijin tinggal yang dimilikinya, sebagaimana yang dimaksud dalam Pasal 116 UndangUndang Nomor. 6 Tahun 2011 Tentang Keimigrasian.

\section{Penerapan pidana denda berdasarkan keputusan Nomor. 11/Pid.C/2016/PN.JKT.BRT}

Sesuai dengan fakta - fakta persidangan, majelis hakim memberikan pertimbangan dan putusannya sebagai berikut : Bahwa Terdakwa bernama Yaya Abraham Nyang, berkebangsaan Gambia telah melakukan tindak pidana yaitu sebagai Warga Negara Asing tidak dapat memperlihatkan dan menyerahkan Dokumen Perjalanan atau izin Tinggal yang sah di Wilayah Kesatuan Republik Indonesia. Memperhatikan ketentuan dalam Pasal 71 Jo. Pasal 116 UndangUndang Nomor 6 Tahun 2011 Tentang Keimigrasian, serta pasal-pasal lain dalam Peraturan Perundang-Undangan yang bersangkutan dan keterangan para saksisaksi.

\section{Putusan Hakim Nomor} 11/Pid.C/2016/PN.JKT.BRT

1. Menyatakan Terdakwa YAYA ABRAHAM NYANG telah terbukti secara sah dan menyakinkan bersalah melakukan tindak pidana keimigrasian "Sebagai Warga Negara Asing tidak dapat meperlihatkan dan menyerahkan Dokumen Perjalanan atau Izin Tinggal yang sah di Wilayah Negara Kesatuan Republik Indonesia".

2. Menjatuhkan pidana denda kepada Terdakwa sebesar Rp. 10.000.000,(sepuluh juta rupiah) dengan ketentuan apabila denda tersebut 
tidak dibayar, maka diganti dengan pidana kurungan selama 1 (satu) bulan.

3. Membebankan biaya perkara kepada Terdakwa sebesar Rp. 2.000,- (dua ribu rupiah).

\section{PENUTUP \\ Kesimpulan}

Tindak Pidana Keimigrasian terhadap pelanggaran Pasal 71 UndangUndang No. 6 Tahun 2011 tentang Keimigrasian, yang berbunyi "Setiap Orang Asing yang berada di wilayah Indonesia wajib memperlihatkan dan menyerahkan dokumen perjalanan atau izin tinggal yang dimilikinya apabila diminta oleh Pejabat Imigrasi yang bertugas dalam rangka pengawasan Keimigrasian". Dilakukan oleh Yaya Abraham Nyang karena perbuatannya pada saat dilakukan pengawasan dan pemeriksaan oleh Pejabat Imigrasi Kelas I Khusus Jakarta Barat diwilayahnya, ketika dimintakan untuk menunjukkan dokumen perjalanan orang asing tersebut tidak dapat memperlihatkan dan menyerahkan dokumen perjalanan yang diminta.

Majelis Hakim memutuskan terdakwa orang asing tersebut dikenakan denda sebesar Rp. 10.0000.000,00 (sepuluh juta rupiah) dengan ketentuan apabla denda tidak dibayarkan maka diganti dengan pidana kurungan selama 1 (satu) bulan, dalam Putusan Nomor 11/Pid.C/2016/PN.JKT.BRT, proses pengambilan keputusan yang dilakukan oleh Majelis Hakim sudah sesuai dengan aturan hukum yang berlaku, yaitu berdasarkan pada keterangan terdakwa, keterangan saksi, keterangan terdakwa sendiri, dan. lalu kemudian mempertimbangkan tentang pertanggungjawaban atas perbuatan yang dilakukan dengan pertimbangan bahwa pada saat melakukan perbuatannya, terdakwa sadar akan akibat yang ditimbulkan.

\section{Saran}

Untuk dilakukan pengawasan dan pemeriksaan orang perorang mengingat lalu lintas keluar masuknya orang asing ke wilayah Negara Indonesia sangat banyak sekali dan Sumber Daya Manusia beserta alat-alat pendukungnya masih belum memadai, sebagai contoh perkara ini ketika orang asing tersebut masuk ke wilayah Negara Indonesia melalui Bandara Soekarno Hatta, sistem telah membaca bahwa orang asing tersebut hanya memiliki masa berlaku paling lambat 60 hari dikarenakan pengawasan serta pemeriksaan tidak dapat dilakukan satu persatu orang perorang dan tidak mungkin untuk ditelusuri setiap orang asing yang masuk ke wilayah Negara Republik Indonesia dengan menggunakan visa kunjungan dan dimana tempat tinggal sementara mereka sehingga antara masing-masing pihak di dalam keimigrasian memiliki kesulitan untuk berkoordinasi dengan kantor imigrasi lainnya untuk dilakukan pengawasan serta pemeriksaan tersebut. Hal ini menjadi celah bagi beberapa orang asing yang memiliki tujuan untuk tinggal lama di Indonesia tetapi visa yang digunakan tidak sesuai dengan tujuannya.

Pelaksanaan sanksi pidana terhadap tindak pidana keimigrasian masih jauh lebih rendah dari pelanggaran terhadap Undang-Undang Nomor 6 Tahun 2011 Tentang Keimigrasian hal ini dapat menjadi celah terulang kembali pelanggaran yang sama. Penulis berharap agar ada peninjauan ulang dari pemerintah untuk pemberian sanksi pidana untuk tindak pidana keimigrasian ini.

\section{DAFTAR PUSTAKA}

Bagir Manan, Hukum Keimigrasian dalam Sistem Hukum Nasional", disampaikan dalam Rapat Kerja Nasional Keimigrasian, Jakarta, 14 Januari 2000.

Burhan Bungi, Analisa Data Penelitian Kualitatif, Pemahaman Filosofi dan Metodologis Kearah Penguasaan Modal Apalikasi, Jakarta, PT Raja Grafindo Persada, 2003.

Dudu Duswara, M, 2002, Pengantar Ilmu Hukum, Refika Aditama Bandung.

Evan J. Criddle \& Evan Fox-Decent, $A$ Fiduaciary Theory of Jus Cogens. Artikel dimuat dalam The Yale 
Journal of International Law, Vol.34 Tahun 2009.

Herlin Wijayanti, Hukum Kewarganegaraan dan Keimigrasian, Malang, Banyuwangi Publishing, 2011.

Dr. Jazim Hamidi, S.H., M.H dan Charles Christian, S.H., M.H, Hukum Keimigrasian Bagi Orang Asing di Indonesia, Jakarta: Sinar Grafika, 2016

Kamus Besar Bahasa Indonesia, Pusat Bahasa Indonesia, edisi ke 4, Departemen Pendidikan Nasional, PT.Gramedia Pustaka Utama, Jakarta 2008.

Lexy J.Moleong, Metode Kualitatif, Bandung, Remaja Rosdakarya, 2004.

Lexy J.Moleong, Metodologi Penelitian Kualitatif, Bandung, Remaja Rosdakarya, 2002.

M. Iman Santoso, Perspektif Imigrasi dalam Pembangunan Ekonomi dan Ketahanan Nasional, UI Press, 2004.

M. Imam Santoso, Perspektif Imigrasi dalam United Nation Convention
Againts Transnational Organized Crime, Jakarta, PNRI, 2007.

Moh. Mahfud MD, Lingkup Kompetensi Peradilan Tata Usaha Negara dan Kapasitas Tuntutan atas satu Keputusan Administrasi, Paper dalam Penataran Hukum Administrasi Negara, Bandung, 1022 Agustus 1987.

Sadjijono, Bab-bab Pokok Hukum Administrasi, Yogyakarta: Laksbang Presindo, 2011.

R. Soeroso, Pengantar Ilmu Hukum Jakarta, Sinar Grafika, 2001.

Ridwan, Hukum Administrasi Negara, Jakarta: Raja Grafindo Persada, 2006

S.F. Marbun, Peradilan Administrasi Negara dan Upaya Administratif di Indonesia, Yogyakarta, Liberty, 1997

Sihar Sihombing, Hukum Imigrasi, Bandung, Nuansa Aulia, 2006

Oloan Sitorus dan Darwinsyah Minin, Cara Penyelesaian Karya Ilmiah Di Bidang Hukum (Panduan Dasar Menuntaskan Skripsi, Tesis dan Disertasi), Yogyakarta,Mitra Kebijakan Tanah Indonesia, 2003. 